\title{
Workplace Diversity
}

\section{"We should All Know that}

Diversity makes for a Rich Tapestry, and we must understand that all the Threads of the Tapestry are equal in value no matter what their color"

-Maya Angelou 



\title{
CASE CHAPTER 4 \\ Managing Diversity through Engagement and Empowerment: A Case from South Korea
}

\author{
Dewan Md Zahurul Islam \\ Bang College of Business, \\ KIMEP University, Almaty, Kazakhstan. \\ mzidewan@kimep.kz
}

\section{Synopsis}

On 14 ${ }^{\text {th }}$ March 2019, Mr. Eric arrived in the Principal, Mr. Xi's, office complaining about the discriminatory actions against him and other new non-native teachers in the South Korean Model School (SKMS). Mr. Eric had the complaints that the native teachers were given less academic burden than that of newly appointed non-natives. Whereas, the old and native teachers were given limited number of activities and were enjoying their leisure time properly. Mr. Xi called Miss Mao, academic coordinator responsible for assigning course work and assignment of duties to the teachers. Mr. Xi inquired about the discrepancy in the assigned tasks.

[...] It is true, she said, we are facing severe resistance from the senior staff for the assignment of additional tasks. They say they are paid less are deserve lesser tasks as compared to the new non-native workers. Also, they say they are seniors, whereas the younger ones are more energetic and can carryon more assignments/tasks than themselves [....]

The resistance was a direct result of Mr. Xi's new diversification of employees' strategy, which had created a sense of insecurity and the discriminatory feeling among the existing employees. The resistance was visible in the form of resistance towards management initiatives, and the students' grades. Mr. Xi had already done much but was still contemplating on what should he do so that he can avoid employee 
resistance and breed positive thinking and cultural empathy among the teachers.

\section{Mr. Xi Nai}

Mr. Xi Nai, 54, a Chinese American, was the newly appointed Principal of South Korea Model School (SKMS). He had a Ph.D. in Education Management from the University of York and a vast academic experience. Switching from one country to another, Mr. Xi had served in four culturally different countries. These included France, Saudi Arabia, the Peoples Republic of China, and the USA. Having the experience of the four entirely different nations, Mr. Xi had joined the NKMS as the Principal in 2016. Mr. Xi was popular because of his unique management style and success history. The history of Mr. Xi shows that he always made some shifts in the schools whenever he joined a new school. As he quoted:

[...]Everyone has their ways of doing things, and I have my own. I believe in managing diversified people requires more of an emphatic leader who has a regard and respect for every culture[....]

\section{South Korean Model School}

The School was a private sector school established in the year 1984. Spread over an area of 3 acres, the School was a state-of-the-art facility in Seoul, South Korea. The school faculty and staff were the South Korean locals who could work on subsidized rates. The male to female ratio was 3:1. Initially, the School served mainly local students. Later in 2000, school management signed a Memorandum of Understanding with the multinational companies for enrolling the children of their employees. Since then, the School got its popularity and became the first choice of expatriates in the region. As time passed, school's condition was changing. The key problems included compromise of quality education and stereotyping and discriminatory attitude of staff and faculty.

Throughout the School's tenure, the leadership kept on changing, and the year 2015 was marked as the worst in terms of school performance. Students' grades were poor, infrastructure deteriorated, 
enrollment declined, and the School was suffering financial losses. Considering the reputation of $\mathrm{Mr}$. Xi as the change agent and diversity manager, he was hired as the Principal of the School.

\section{Mr. Xi's Role as an Agent of Change}

As Mr. Xi arrived in the School, he began to learn the School's existing culture. As he stated

[...] The school problems were visible in the enrollment, profitability, and attendance sheets.

To unearth the causes of those problems, we had to follow a rigorous and systematic process. So rather than imposing my systems and SOPs, which I practiced somewhere else, I began to learn the existing policies and SOPs and the underlying logic. So that, where necessary, I may change them for positive outcomes [....]

Comprehensively, Mr. Xi began to learn the system of the School. Through official documents and records, formal and informal meetings with the faculty and staff members, parents, students, and the board, he came to know about the underlying causes of the School's backwardness. He then began to document them.

\section{Board Meeting and the Proposed Re-orientation of School Culture}

After three months, he presented his findings before the Board of Directors. In the presentation, he showed the declining students' grades, increment in students and parental complaints, and the lowered profits. The presentation was a gist of Mr. Xi's past three months' research. He highlighted the comments of a few of the expatriates and their children. The comments could read as follows:

[...] Teachers are un-attentive to our kids, Asian kids, particularly the east Asian kids, get more attention of the teachers and are gently treated than the westerns. A British expatriate commented [....]

[....] Our kids are easily ridiculed for their accent. Said an Indian parent [....]

Besides, the descriptive statistics showed a considerable diversity containing Indian, Chinese, African, American, and the British students enrolled in the School along with the local public (See Exhibit 01 for diversity). 
In his presentation, Mr. Xi highlighted causes such as student-teacher ratio, stereotyping and discrimination, limited role of faculty and staff members in administrative activities, and lack of engagement and empowerment at the staff levels. The solutions that Mr. Xi presented were to hire additional and other nationality holder faculty and staff and engage them in diversified tasks so that they may contribute in the overall uplifting of the School rather than just sticking to their customary routine tasks along with some significant changes in the School's Vision, mission, codes and conducts, pedagogies, infrastructure, and the staff. His proposal was accepted, and the next step was to incorporate the proposed changes.

\section{Change in Vision \& Mission}

After his evaluative study of the School during the initial months, Mr. Xi learned that the School's guidelines were obsolete and required to be revisited. Former Vision, mission, codes, and conducts lacked the measures for the diversity. So, he took this opportunity and converted the old Vision and mission into the new Vision and mission that include the element of diversity (See appendix for new Vision and mission). Mr. Xi quoted:

[....] Vision and mission are the core that provides a pathway for the School and its stakeholders to work in the best interest of the School. And our School was operating with the old Vision and mission, mainly lacking diversity emphasis. Therefore, a change in the official guidelines was a must [....]

\section{Diversity Criteria and Diversity Hiring}

To execute his diversity suggestion, Mr. Xi had to decide which country nationals to choose and what number of those foreign teachers to hire. For this, he developed diversity criteria for matching the number of international students and respective teachers and based on the number of students hiring the required number of students that is one teacher per 25 students.

[...] The criteria were necessary so that may not ignite any further discriminatory issue[...] 
Based on the diversity criteria results, he forwarded employee requisition to the HR department and hired additional staff as needed. The other country, nationals demanded more salaries as compared to locals. Mr. Xi agreed to pay them and quoted:

[...] To address the stereotyping and discriminant thinking, we had to foster in a diversified culture in the staff level as well so that the students' problems may properly be addressed and more buy-in of the students and family members should be ensured [....]

\section{Diversity Training and Socialization}

Hiring staff was just an initial step. The next step was the smooth transition of these employees. Therefore, Mr. Xi planned the diversity training and socialization of these employees. The diversity training program consisted of the thrice a year training session aimed at understanding and enhancing empathic feelings of the staff members towards other cultures. As one of the old faculty members quoted:

[...] The training sessions helped us overcome stereotypical barriers and helped us understand other cultures. Rather than working alone, it helped us work effectively in the diversified teams. The training also equipped the employees with the necessary internationally accepted etiquettes and dos and donts of each culture. So that everyone may learn every other culture hence avoid the behavioral and discriminatory issues [....]

Besides, Mr. Xi introduced formal and informal socialization programs that aimed at removing communication barriers and to avoid the unnecessary wastage of time on group development. Another staff member quoted:

[...] The weekly meetings are part of our formal socialization program, whereas sitting together in recess timings, staff dinners, and celebrations are also part of the socialization program. Together, all mainly aimed to achieve one common goal that is shared Vision [...]

\section{Major Shifts in Roles and Responsibilities and Organogram}

Mr. Xi was known for bringing major shifts into the systems whenever he moved to a new place. Similarly, he came up with some of the major shifts in the roles and responsibilities of the employees. Earlier, employees were only doing similar but limited number of repetitive 
tasks. A teacher was only focused on the teaching, but Mr. Xi enhanced their roles by assigning them hostel administration and liaising duties, mentorship and, counselling roles, also making them focal persons for various academic projects and exhibitions. As commented Mr. Xi:

[....] Previously, our staff was limited to the same routine tasks, adding more tasks may enhance their engagement and enhance their feelings of empowerment in the School. Now the same teachers participate in the management meetings and give their feedback in enhancing school performance. They set objectives by themselves and achieve them [....]

\section{Lessening Controls}

Earlier, there had been more and more controls at every layer of hierarchy at School??? Hindering communication and enhancing the School's cost in terms of employees' salaries. Therefore, Mr. Xi demanded a cut of additional controls in the hierarchy. (See Exhibit 02 and 03). As mentioned by a Miss Mao:

[...] For our performance evaluation, our academic coordinators or the HR personnel usually visited the classroom. Due to which we always had to remain vigilant and serious, whereas for developing students' interests, we had to maintain a bit of free environment so that student retention should be high. These control not only limited teachers' normal behavior with the students but also hindered their out of the box practices [....]

\section{Infrastructural and Pedagogical Developments}

Another step that Mr. Xi took to foster a positive mindset towards other cultures was to incorporate major infrastructural changes. These changes include the first renovation of walls. Previously there were academic wall paintings only, so to promote diversity education, Mr. Xi got the main wall of the library painted with different nationality boys and girls studying together. The language of the paintings was converted into a common language that was English. He strictly asked the teachers to create cross nationality groups in the classroom activities so that students may socialize and feel at ease when communicating with each other. Classroom furniture was replaced with more interactive designs where students were assigned to sit in a diversified manner. Emphasis on the English language as a medium of communication was promoted. 
The curriculum was revised to include contemporary cultures. Teachers were asked to change their teaching patterns and provide equal time for every student.

\section{Enhancing Student Enrollment through Re-liaising and Promotion}

For students' overall grooming, Mr. Xi encouraged students' participation in competitions and exhibitions. Students began to participate in the history, science, and arts and sports competitions and events. The school management reaped two benefits from it. They posted their students' achievements on social media and making it public so that existing students may feel recognized and to attract other new students in the region. To increase student enrollment, $\mathrm{Mr}$. $\mathrm{Xi}$ adopted various marketing approaches, mainly the print and social media.

Besides, retaining the existing students, $\mathrm{Mr}$. Xi assigned every teacher to have one to one teacher-parent meetings. Mr. Xi particularly focused that the meetings should take place between the same nationality teacher and parents so that parents get better responses.

One of the parents quoted:

[...] We were planning to leave the School, but then had a meeting with Miss. Elizabeth, we felt at ease, and she briefed us about the recent changes at the School. We were comfortable after when she briefed us. Later on, we cancelled our intention to leave the School $[. . .$.

\section{Success of the School}

Once the major changes were incorporated, slowly, School began to witness success in the form of increased profits, growing number of students' enrollment, lowered dropout ratio, and significant improvement in students' grades. Years passed, and the students' enrollment reached around 1900, the total number of faculty members reached 76 , staff number turned 45 .

Additionally, eight contracts were signed with multinational companies for their expatriates working in South Korea. But this was just the tip of the iceberg. On the other hand, a lobby of native Koreans was 
catching fire. At first, this was visible in the grade differences of natives in comparison to the other nationals. With this decision, this group was suffering the most in terms of employment benefits. So, they began to lobby. Slowly, their resistance began to increase. Frequent rejections for the new plans, resistance to the compensation of the School, using their internal lobbying was providing easy subjects to their favorites, assigning hectic and burdensome tasks to the new ones.

This type of resistance began to create problems on $4^{\text {th }}$ of the March when Mr. Eric arrived in Mr. Xi's office. He complained about the discriminatory action against him and the other new teachers. He had been assigned more tasks as compared to other senior and native teachers in the School.

We are always assigned some difficult subjects. He said we actively participate in the exhibitions, mentorship activities, and the counselling sessions, whereas the other native teachers get lesser tasks than us and enjoy their rest of the time in their leisure.

Mr. Xi called Miss Mao and inquired about the discrepancy of the assigned tasks.

It is true, she said, we are facing severe resistance from the senior staff for the assignment of additional tasks. They say they are paid less are deserve lesser tasks as compared to the new non-native workers. Also, they say they are seniors, whereas the younger ones are more energetic and can carryon more assignments/tasks than themselves. Additional duties are the part of employees' citizenship behavior, which old employees resist to contribute.

The resistance was a direct reaction that arose from Mr. Xi's new diversification of employees' strategy, which had created a sense of insecurity and discriminatory feeling among the existing employees. The resistance was visible in the form of management initiatives, and discrimination was evident in students' grades. Mr. Xi was now contemplating on what he should do so to avoid employee resistance and breed positive thinking and cultural empathy among the native/local teachers. 


\section{Appendix 01: Vision \& Mission}

We aim to enhance and empower students and teachers to acquire, exhibit, create and make ethical use of knowledge and skills to support themselves and the society and practice respect, tolerance, empathy, and excellence in the global world.

\section{Mission}

Our mission is to enable students to access learning opportunities through:

- Learned, effective, and ethical teachers.

- Modern curriculum and teaching pedagogies.

- Care and respect for other ethnic and diverse groups.

- Engaging, Empowering, and Enriching resources.

- Providing equal opportunities for teachers, parents, and community to participate in decision making.

\section{Exhibit 1: Diversity Hiring Criteria Table}

\section{Diversity Criteria Table}

\begin{tabular}{|c|l|c|c|c|c|}
\hline $\begin{array}{c}\text { S. } \\
\text { No }\end{array}$ & Nationality & $\begin{array}{c}\text { Total } \\
\text { Number of } \\
\text { Students }\end{array}$ & $\begin{array}{c}\text { Student \% } \\
\text { in School }\end{array}$ & $\begin{array}{c}\text { No. of } \\
\text { Students }\end{array}$ & $\begin{array}{c}\text { Required } \\
\text { Number of } \\
\text { Teachers }\end{array}$ \\
\hline 1 & South Korean & 1900 & $55 \%$ & 1045 & 42 \\
\hline 2 & American & 1900 & $15 \%$ & 285 & 11 \\
\hline 3 & Indian & 1900 & $12 \%$ & 228 & 9 \\
\hline 4 & Chinese & 1900 & $10 \%$ & 190 & 8 \\
\hline 5 & Britisher & 1900 & $5 \%$ & 95 & 4 \\
\hline 6 & African & 1900 & $3 \%$ & 57 & 2 \\
\hline
\end{tabular}




\section{Exhibit 2: Former Organogram}

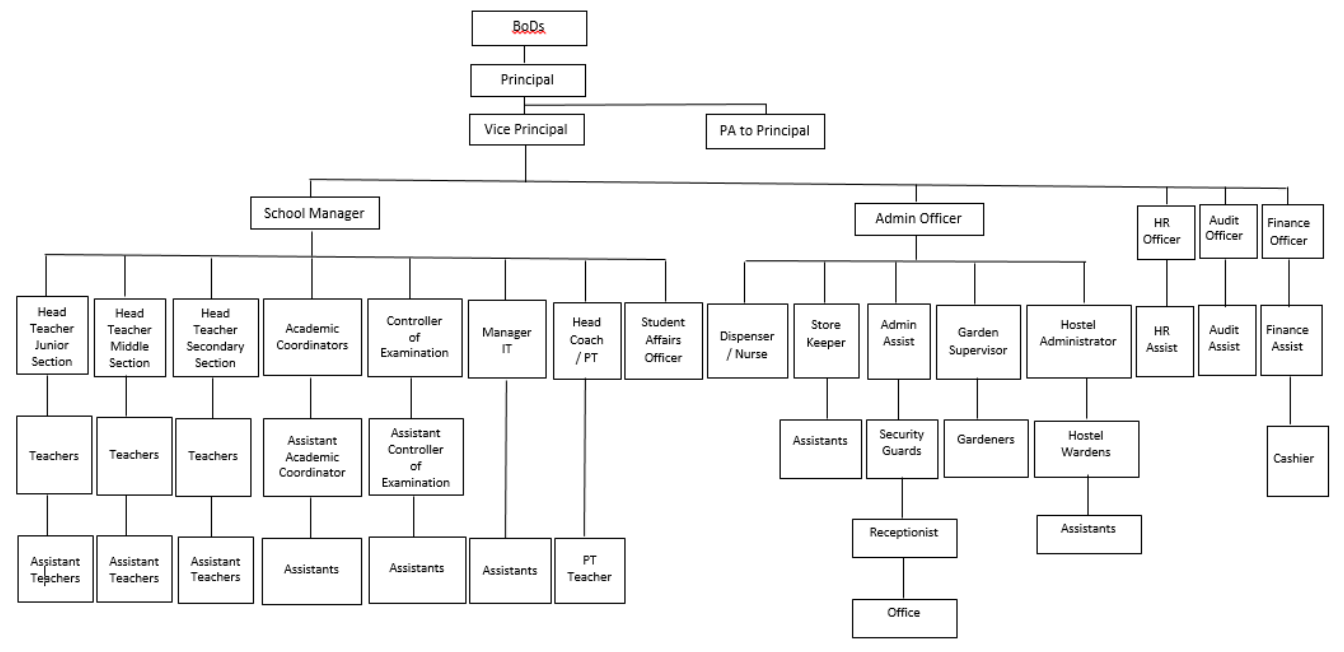

\section{Exhibit 3: New Organogram}

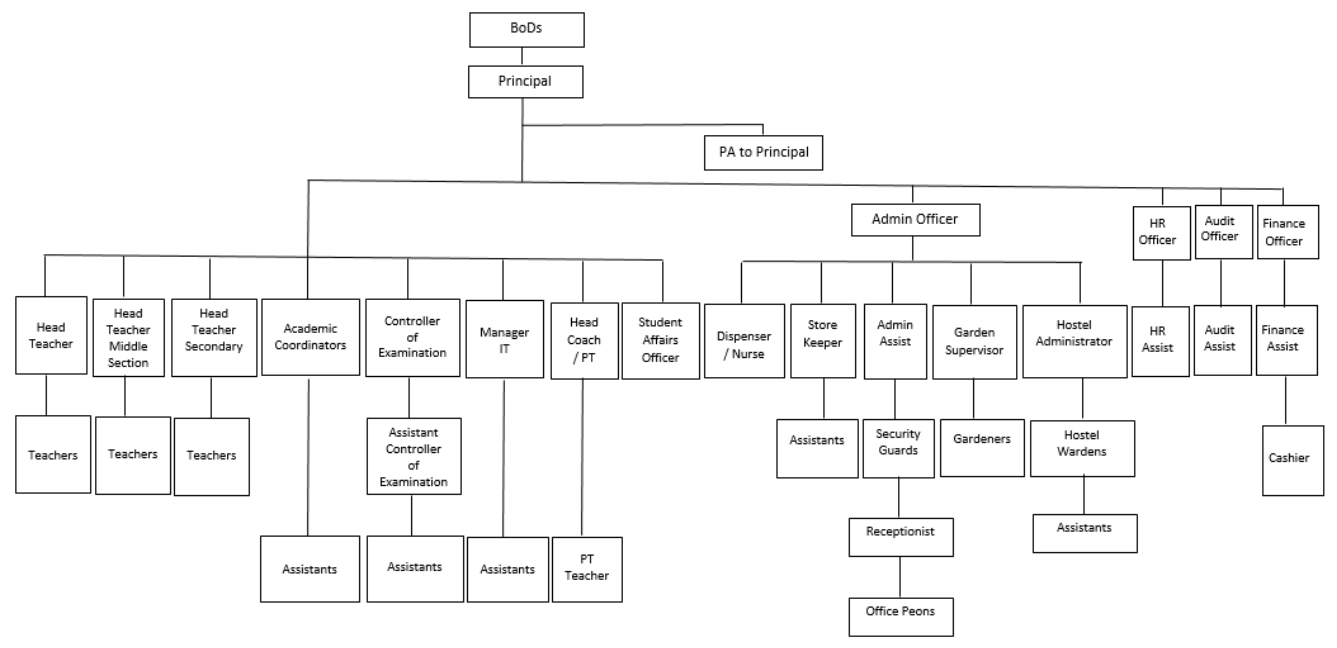

\section{Discussion Questions}

Q1. Discuss why Mr. Xi concluded that change should take place in the system. Discuss in the light of forces for change.

Q2. Identify the causes of resistance.

Q3. Based on the types of change, categorize the changes that Mr. Xi brought in the School. 
Q4. Discuss the structural, process, and boundary??? Changes that Mr. Xi brought in the School.

Q5. What should Mr. Xi do?

\section{Suggested Readings}

Lumby, J., \& Coleman, M. (2007). Leadership and diversity: Challenging theory and practice in education. Sage.

Morrison, M., Lumby, J., \& Sood, K. (2006). Diversity and diversity management: Messages from recent research. Educational Management Administration $\mathcal{E}$ Leadership, 34(3), 277-295.

Palmer, I., Dunford, R., Akin, G., \& Buchanan, D. A. (2009). Managing organizational change: A multiple perspectives approach. New York: McGraw-Hill Irwin.

Thomas, R. R. (2010). World class diversity management: A strategic approach. Berrett-Koehler Publishers.

(C) 2020 by the author(s). Published by Annals of Emerging Technologies in Computing (AETiC), under the terms and conditions of the Creative Commons Attribution (CC BY) license which can be accessed at http://creativecommons.org/licenses/by/4.0. 